\title{
Chapter 2 \\ Mapping the Policy Interventions on Marine Social-Ecological Systems: Case Study of Sekisei Lagoon, Southwest Japan
}

\author{
Mitsutaku Makino, Masakazu Hori, Atsushi Nanami, Juri Hori, \\ and Hidetomo Tajima
}

\begin{abstract}
Using a case of the Sekisei Lagoon, Okinawa Prefecture, the southeastern tip of Japanese archipelago, this chapter discussed the interrelationships among the sectoral policy interventions by various marine-related ministries, and the whole structure of the integrated ocean policy. First, we developed the SocialEcological Systems (SES) Schematic, which summarized the main ecosystem structures, functions, use types, and the stakeholders relating to the Sekisei Lagoon. Then, sectoral policy interventions by various ministries were overlaid onto the SES schematic to graphically show their interrelationships. We found that the ecosystem structure and functions used by one sector is closely connected to other structures and functions, which are then used by other sectors. In other words, all the stakeholders in the social system are closely interlinked at the ecological system level. Secondly, all in all, sectoral policy interventions by various ministries are covering almost all part of the Sekisei Lagoon SES, and therefore, the total coordination of the sectoral policy interventions and the creation of the synergy effects are required. In this process, the cabinet office and the local government
\end{abstract}

M. Makino $(\bowtie)$

Atmosphere and Ocean Research Institute, University of Tokyo, Chiba, Japan

e-mail: mmakino@aori.u-tokyo.ac.jp

M. Hori

National Research Institute of Fisheries and Environment of Inland Sea, Japan Fisheries

Research and Education Agency, Yokohama, Japan

A. Nanami

Research Center for Subtropical Fisheries, Seikai National Fisheries Research Institute, Japan

Fisheries Research and Education Agency, Ishigaki, Japan

J. Hori

Education Unit for Studies on Connectivity of Hills, Humans and Oceans, Kyoto University,

Kyoto, Japan

H. Tajima

Japan Fisheries Education and Research Agency, Yokohama, Japan

(C) The Author(s) 2020

O. Saito et al. (eds.), Managing Socio-ecological Production Landscapes and

Seascapes for Sustainable Communities in Asia, Science for Sustainable

Societies, https://doi.org/10.1007/978-981-15-1133-2_2 
will play the important roles. Finally, this SES schematic can be used as a boundary object to facilitate the knowledge exchanges among various stakeholders including the policy makers, practitioners, and researchers, to share the common understandings of the current situation, and to cocreate the policy interventions for the sustainable uses of Sekisei Lagoon.

Keywords Integrated ocean policy · Sectoral policy interventions $\cdot$ Socialecological systems (SES) schematic · Mapping · Stakeholders · Sekisei Lagoon

\subsection{Introduction}

\subsubsection{Ocean Policy in Japan}

In Japan, eight ministries are implementing marine-related policies, i.e., Ministry of Agriculture, Forestry and Fishery: MAFF, Ministry of Environment: MoE, Ministry of Land, Infrastructure, Transport and Tourism: MLIT, Ministry of Education, Culture, Sports, Science and Technology: MEXT, Ministry of Economy Trade and Industry: METI, Ministry of Internal Affairs and Communications: MIC, Ministry of Foreign Affairs: MFA, and Ministry of Defense: MoD. Each ministry has its own policy missions, legal basis, marine use-types under the jurisdiction, and stakeholders. Traditionally, each ministry has been implementing its specific policy interventions separately and independently (often called as "sectoral policy interventions"). As the result, it has not been clear enough how the Japanese ocean policy, as a whole, would deal with the up-to-date issues such as environmental degradation, overfishing, integrated coastal zone management, national security, etc. Therefore, in 2007, in order to promote the coordination among sectoral policies interventions by eight ministries and to formulate the integrated ocean policy, the Basic Act on Ocean Policy (hereafter, the Act) was legislated (Sakamoto 2018; Makino 2011). Based on the Act, the Headquarter for the Ocean Policy was formulated at the Cabinet Secretariat of Japan (moved to the Cabinet Office in 2017), headed directly by the Prime Minister.

\subsubsection{Objective of This Chapter}

Conventionally, a lot of assessments and analysis have been conducted on the design or effectiveness of the sectoral policy interventions, and therefore analytical methodologies for that purpose have been developed (For example, Dunn 2016; Weimer and Vining 2017). Recently, many studies have been conducted on the 
interrelationships among the sectoral policy interventions by each ministry, and on the comprehensive design or the effectiveness of the integrated ocean policy as a whole (for example, Cicin-Sain and Knecht 1998; Guneroglu 2015). Also, marine ecosystems have high uncertainties and fluctuations with very limited scientific knowledge. And because the objective of the ecosystem conservation are "the matter of societal choices" (Principle 1 of the Ecosystem Approach of the Convention on Biological Diversity), the expected effects by policy interventions to the stakeholders are important information for the social agreement and the effective coimplementation of the policy interventions (Ban et al. 2013; Ehler 2014; Kittinger et al. 2014; Schultz et al. 2015; Bodin 2017). Therefore, using a case of the Sekisei Lagoon, Ishigaki City, Okinawa Prefecture, Japan (Fig. 2.1), this chapter tried to understand and to analyze the whole structure of the marine-related policy measures introduced by various ministries, and their interrelationships with not only the ecosystem structures and functions but also with the various use types and stakeholders. Especially, based on the first Basic Principle of the Act (Article 2), this chapter focused on the policy interventions for "Harmonization of the Development and Use of the Oceans with the Conservation of Marine Environment".

There are many types of uses in the Sekisei Lagoon. Traditionally, the fisheries resources at the very nearshore coastal area have been utilized by the local people at the daily basis and it constitutes an important part of local culture (Sugimoto 2016). The main commercial uses are the fishery and tourism. Because it is remoted islands area, marine transport (people, food, goods, etc.) are also very important. In addition, the environmental education and research activities by local schools and NGOs (for example, the WWF Japan) are very active here. On the other hand, for the last few decades, the coral reefs have been widely destroyed and deteriorated presumably by the over uses by various stakeholders, impacts from the land, and the effects from climate change. To deal with this issue, the "Sekisei Lagoon Nature Restoration Committee" was established and variety of policy interventions have been implemented here (Lou et al. 2017).

Fig. 2.1 Location of the Sekisei Lagoon, Ishigaki City, Okinawa Prefecture

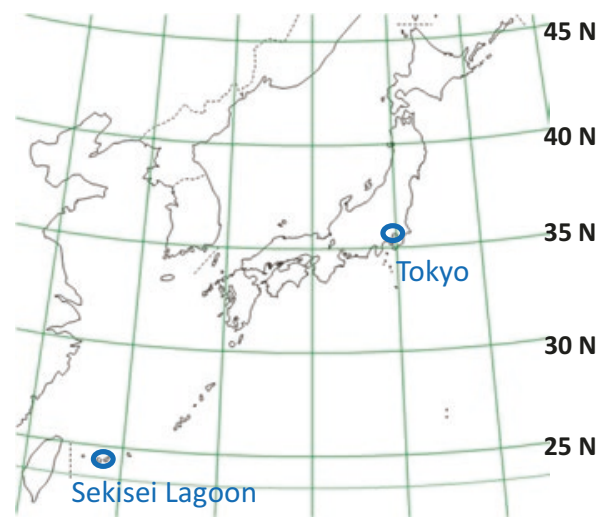




\subsection{Method}

\subsubsection{The Social-Ecological Systems (SES) Schematic}

There are many ways to conceptualize the interrelationships between ecological system and social systems (For example, Ostrom 2009, Berkes et al. 2014, Bodin 2017, Diaz et al. 2018, etc.) Some studies drew social-ecological diagram based on the interviews/workshops with local stakeholders. For example, Howard et al. (2013) dealt with the climate change in Australia and discussed the marine biodiversity conservation scenarios with stakeholders. Tiller et al. (2017) discussed about the governance of Norwegian salmon aquaculture with local stakeholders and government officers, and developed the conceptual map. In this chapter, because our study focused on the policy interventions for harmonization of the uses and conservation (Article 2 of the Act), we tried to describe the interrelationship among the main ecosystem structures, ecosystem functions, ecosystem use types, and stakeholders, in the following manner.

Firstly, the ecological scientists in the co-authors conducted the literature reviews and hearing survey to biologists, ecologists, fisheries scientists, etc., who are doing natural science researches on the Sekisei Lagoon, and identified the important ecosystem structure and functions there. On the other hand, the social scientists in the coauthors conducted the web-based survey to identify the main stakeholders relating to the marine ecosystem services (Hori et al. 2017). Based on the result, they conducted the field stakeholder analysis in Ishigaki City (snowball method interviews) to identify the main use-types of the Sekisei Lagoon ecosystem services. They interviewed to the local fishers, agricultural farmers, local/national government officers, coast guard, local researchers, environmental NGOs (including WWF-Japan), tourism association, diving association, restaurants, ferry company, and local hotels. Finally, these results are combined into an integrated diagram, called as the Sekisei Lagoon Social-Ecological Systems (SES) Schematic.

\subsubsection{Review of the Policy Interventions}

Based on the Sekisei Lagoon SES Schematic, literature reviews and interviews were conducted to the local/central government officers and environmental policy experts, and a list of main legal basis (acts) relating to the policy interventions to the Sekisei Lagoon by various ministries was developed. Then, coauthors identified the components within the Sekisei Lagoon SES Schematic that each policy intervention by each ministry is targeting. Finally, the coverages of the overall policy interventions by various ministries were graphically summarized over the SES Schematic (Makino et al. 2018). 


\subsection{Results}

Figure 2.2 is the Sekisei Lagoon SES Schematic developed by the authors. It shows that the ecosystem functions in the coastal areas, in which the reef building corals locate, are closely linked to the land, intertidal, and the offshore ecosystems. For example, juvenile fish grew up in the nursery ground at the intertidal area, which is under the heavy influences from the land discharges, and then inhabit to the coral reef areas where fisheries operations are conducted. Also, it shows the wide-ranging ecosystem functions have been utilized by various use types and stakeholders. For example, fisheries sector (fishers, processors, retailers, etc.) are relying on the ecosystem functions such as nursery ground, spawning ground, feeding area, etc., for harvesting fish. The same functions are also utilized by other sectors such as the tourism sector.

Table 2.1 summarized the government bodies, legal basis (acts), and their target components in the Sekisei Lagoon SES Schematic. There are more than 50 acts under the charge of at least five ministries and local government (Okinawa Prefecture and Ishigaki City). Note that, the policy measures relating to the MoD, are important, but not directly relating to the ecosystem of the Sekisei Lagoon. Therefore, they are excluded from this analysis. Also, there is a territorial issue in Ishigaki City, and therefore policy interventions by the MFA are important, but it was excluded based on the same reason. METI is mainly in charge of the marine renewable energy development such as offshore wind power, or sea bottom resource development such as submarine manganese nodules or cobalt-rich crust, both of them are not existing around the Sekisei Lagoon at the moment. MIC is mainly in charge of the information and communication technologies for vessels or communities in the remoted islands, which is again not the case in the Sekisei Lagoon.

Finally, Figs. 2.3, 2.4, 2.5, 2.6, 2.7, and 2.8 graphically summarized the coverage of each sectoral policy interventions on the SES Schematic. The dark color shows the direct and stronger relationships (double circles in Table 2.1), while light color shows the indirect and weaker relationships (single circles in Table 2.1). The characteristics of each sectoral policy are clearly illustrated. For example, MAFF measures (Fig. 2.4) are targeting the ecosystem functions and structures directly relating to the fisheries resources and agriculture on land, while MoE measures (Fig. 2.3) are more about the water quality or waste/soil management, as well as the nature restoration activities for coral reefs such as the management of the "Sekisei Lagoon Nature Restoration Committee". MLIT (Fig. 2.5) is in charge of tourism and transport, as well as the land development on the island. As shown in Fig. 2.6, MEXT's main policy target is research, education, monitoring, and the conservation of the natural/cultural monuments. The Cabinet Office (Fig. 2.8) are covering almost all part of the SES based on the national-scale plans or strategies such as Ocean Basic Plan, Marine Biodiversity Conservation Strategy, Okinawa Promotion and Development Plan, etc. Similarly, the local government has similar plans/strategies and covering almost all the SES components (Fig. 2.7). 


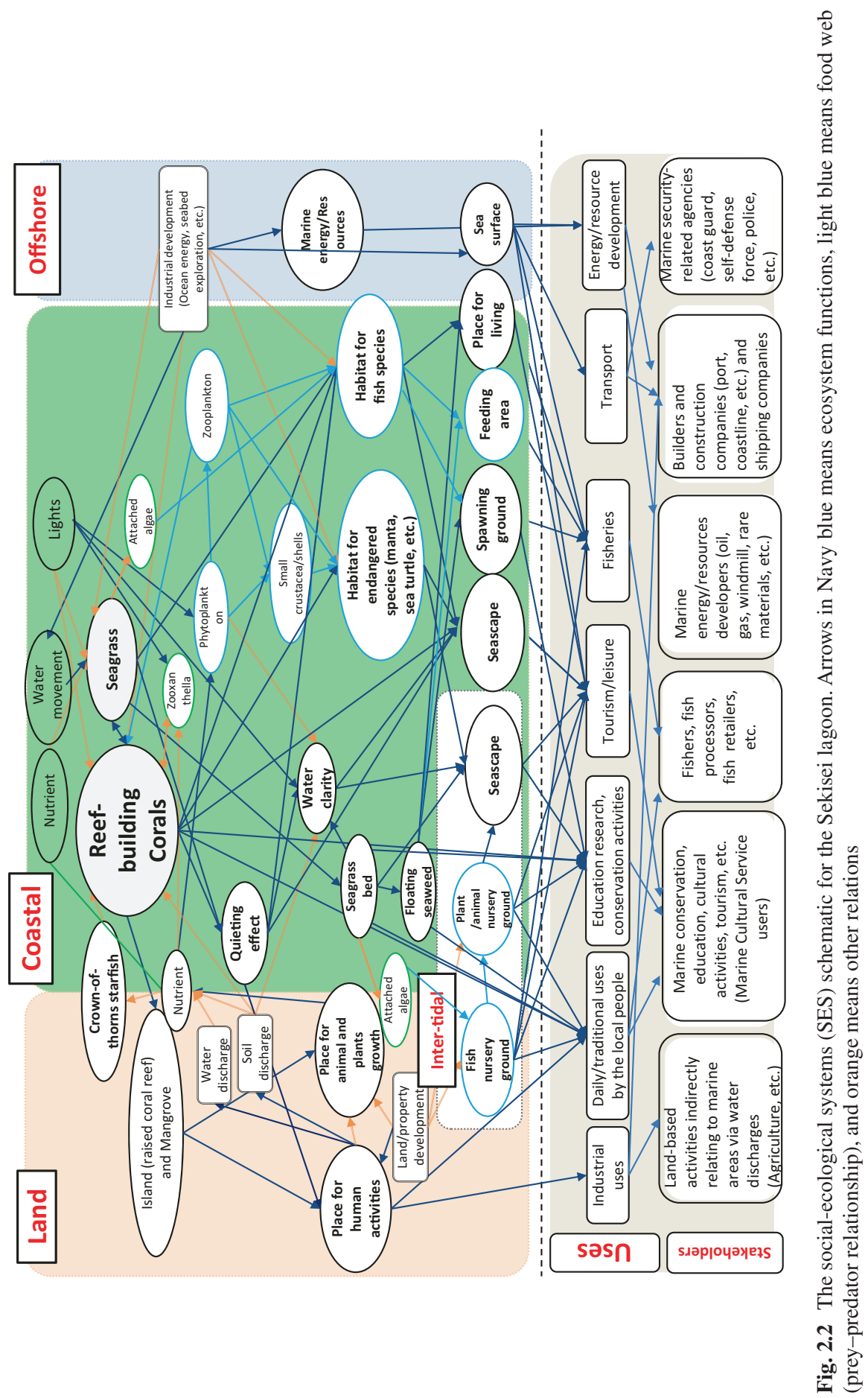




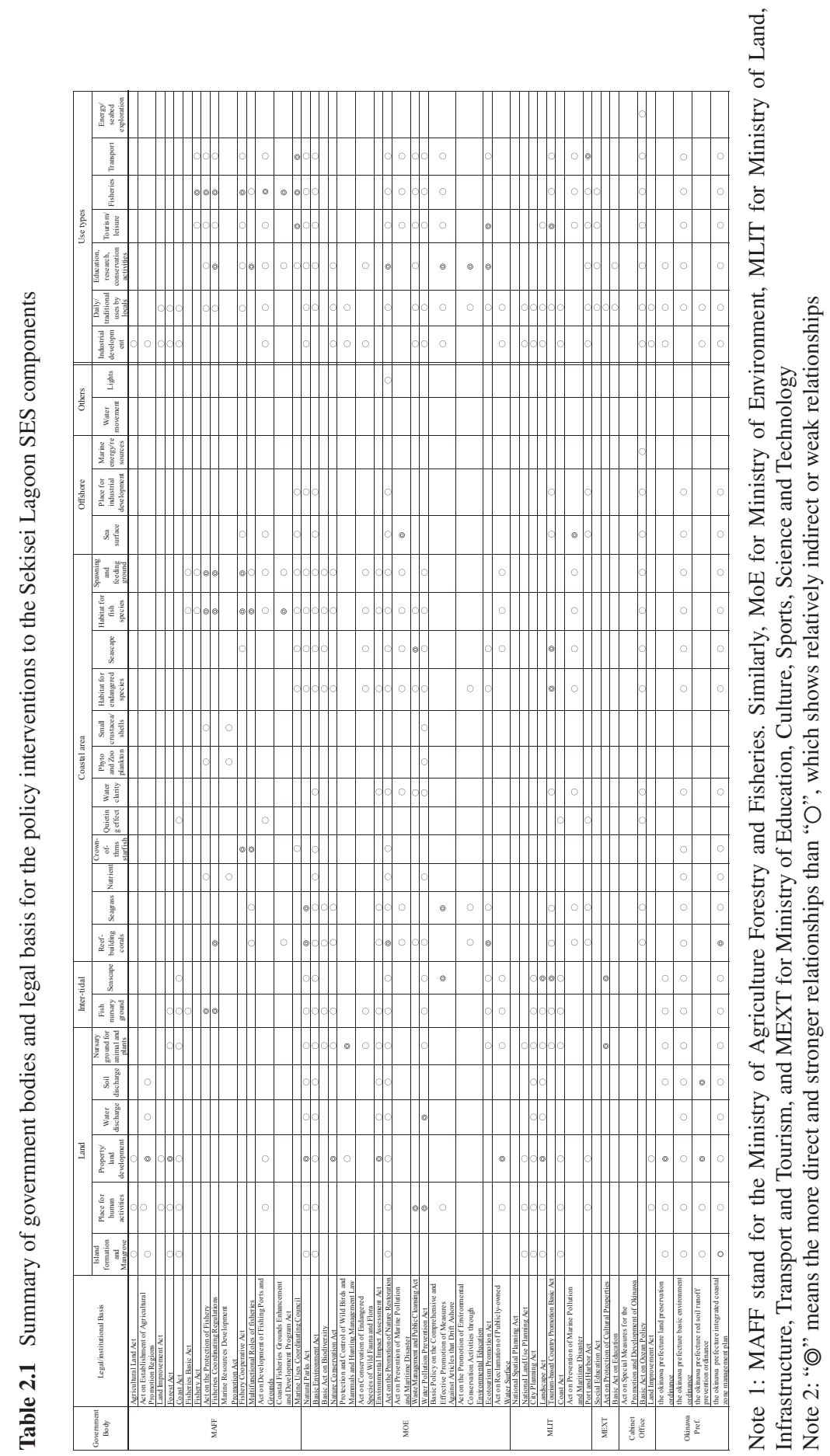




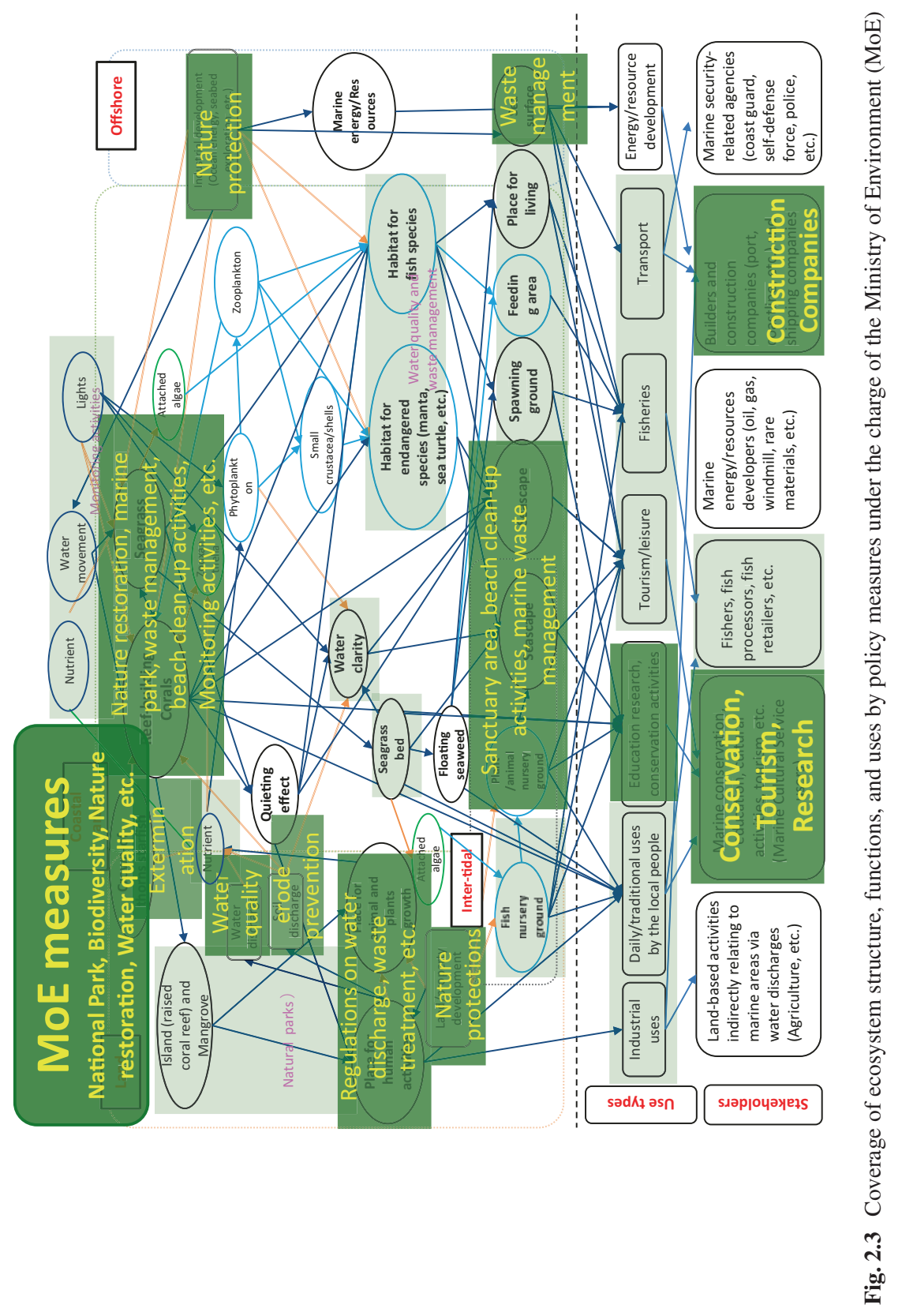









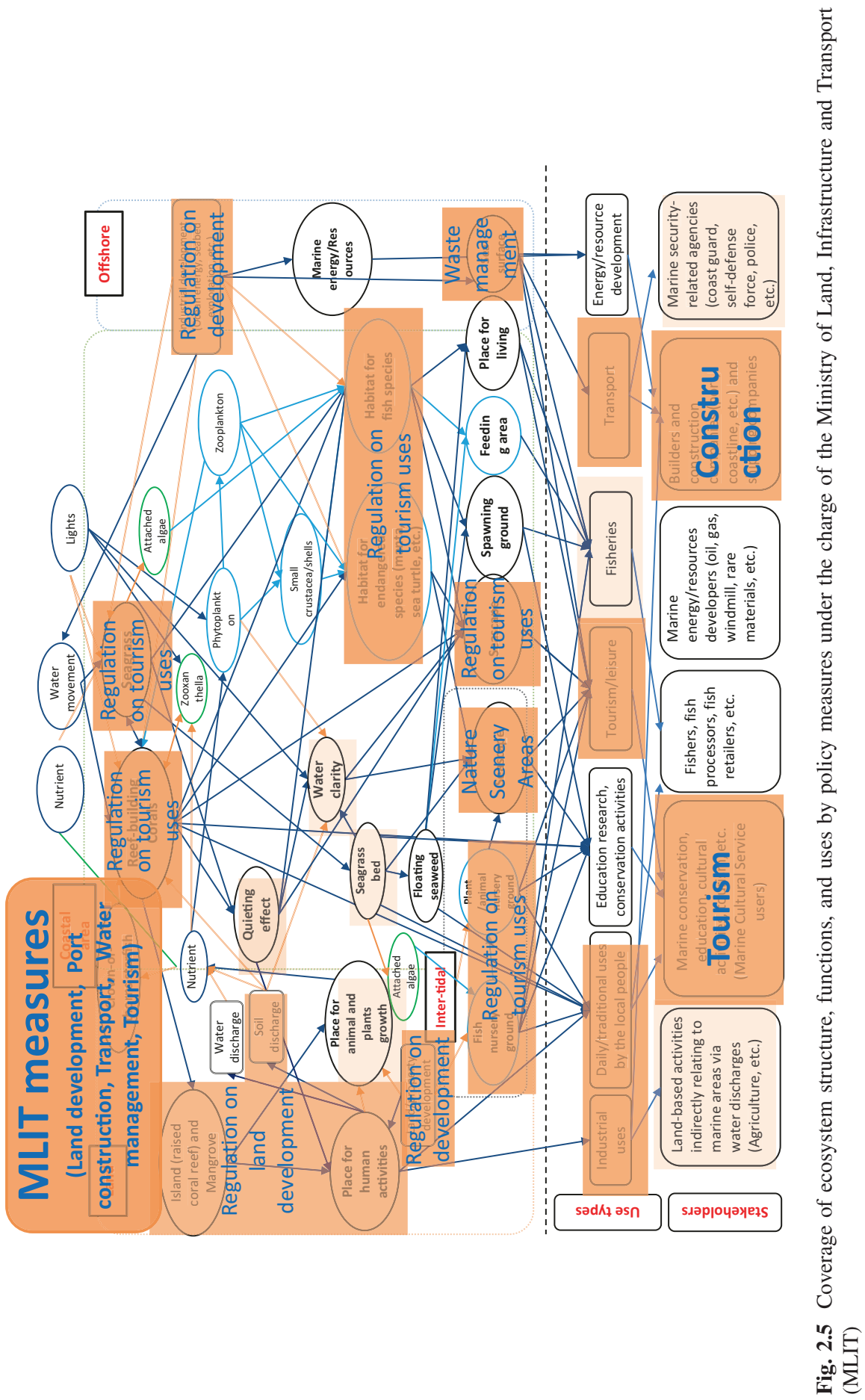




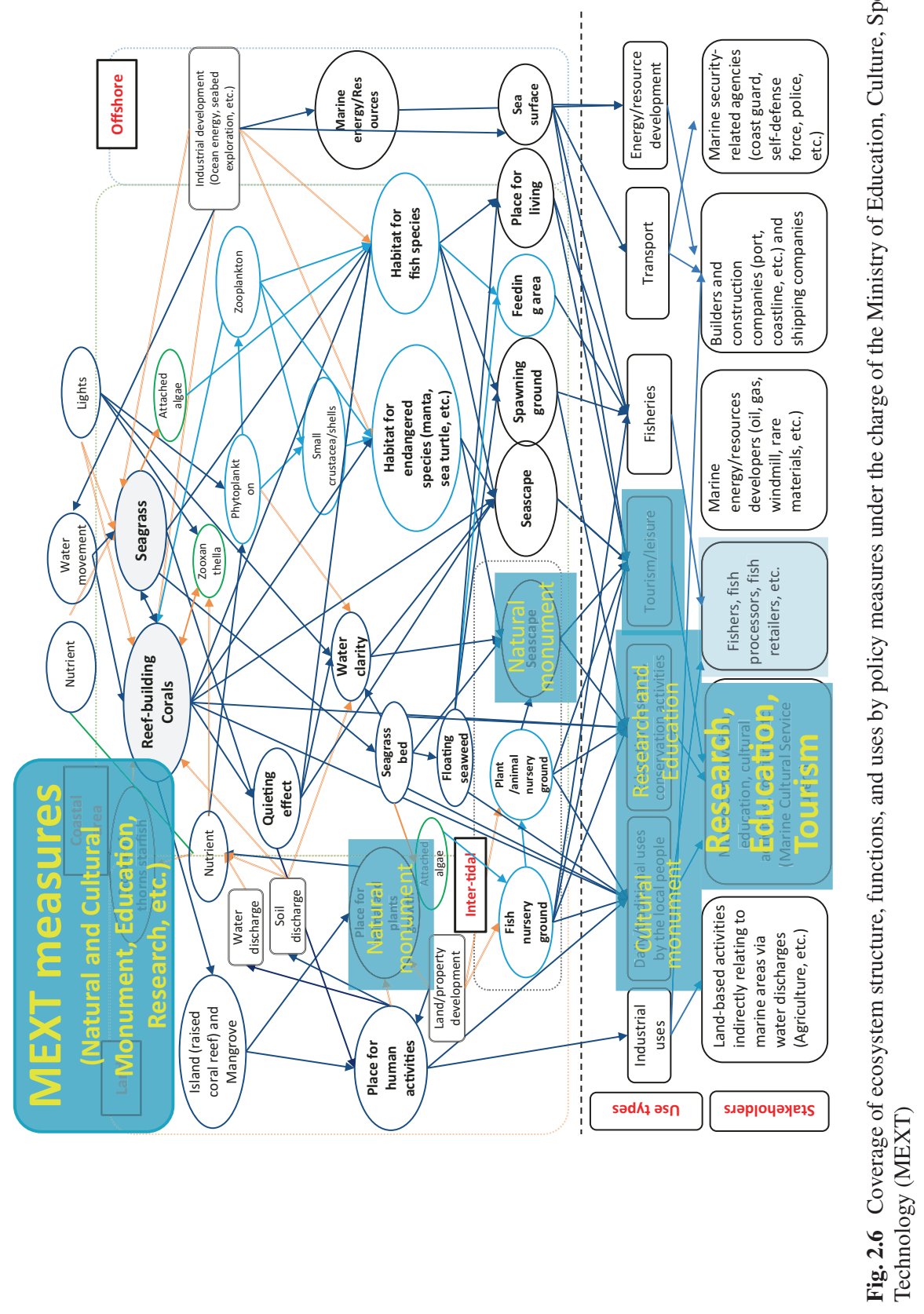




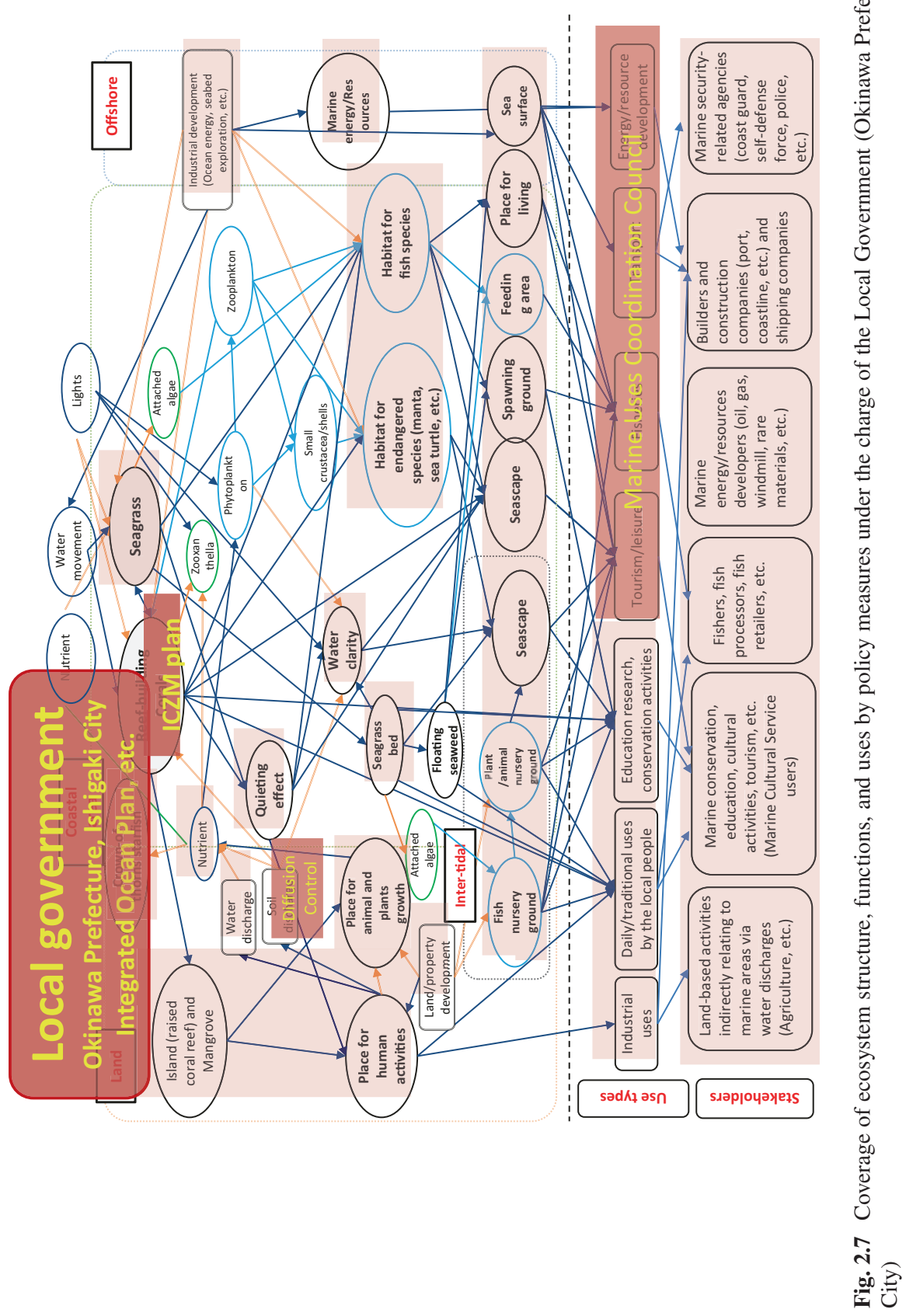




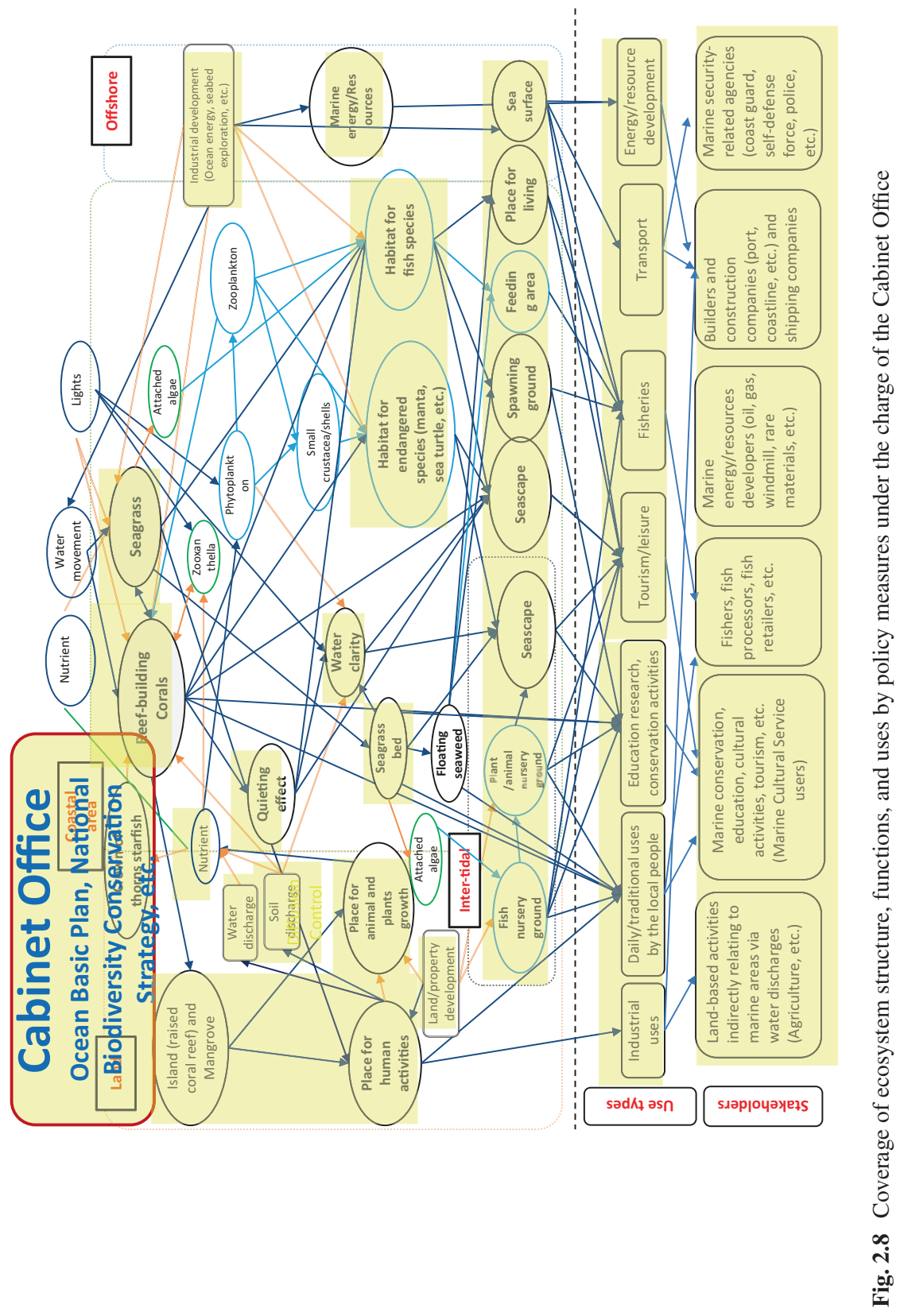




\subsection{Discussions}

\subsubsection{SES Schematic as a Boundary Object}

This chapter tried to graphically summarize the main ecosystem structure, functions, use types and the stakeholders of the Sekisei Lagoon, and then link them to the various ministries and legal basis for the policy interventions. This is a genuine interdisciplinary work for understanding the coastal social-ecological systems (Armitage et al. 2017). This schematic can be used as a boundary object (Star and Griesemar 1989; Cash et al. 2003) to facilitate the knowledge exchanges among various stakeholders, to share the common understandings of the current situation, and to cocreate the innovative governance activities for the sustainable uses of the Sekisei Lagoon. As Reed et al. (2014) pointed out, inclusion of the stakeholders into the knowledge exchange scheme from the very early stage of a research project is important and effective option for the continued motivation and engagement by the stakeholders. Similarly, the knowledge exchange between researchers and decisionmakers is important for effectively implementing the adaptive governance of the marine resources (Cvitanovic et al. 2015). Indeed, during the interviews about the policy interventions, the government officers and environmental policy experts often said to us that this SES schematic is useful to identify their administrative jurisdictions from a wider point of view, and to understand the interrelationships with other ministries or other sectors.

\subsubsection{Integration of the Sectoral Policies and the Multilevel Governance}

It is clearly shown in Fig. 2.2 that, the ecosystem structure and functions used by a certain stakeholder is closely connected to other structures and functions, which are then used by other sectors. Therefore, for example, environmental policy interventions for biodiversity conservation are also important for and effective to the sustainable fisheries (Friedman et al. 2018). This is one of the strongest messages made by the SES Schematic analysis.

Figures 2.2, 2.3, 2.3, 2.4, and 2.5 show that the majority of SES components are covered by some sectoral policy interventions by MoE, MAFF, MLIT, and MEXT. Therefore, all in all, sectoral policy interventions are covering the majority of the Sekisei Lagoon SES. This is the second strongest finding from this study. It means, the only remained task is the coordination from the viewpoint of the integrated ocean policy as a whole and the creation of the synergy effects. Theoretically, as Table 2.1 and Figs. 2.7 and 2.8 show, the local government and the Cabinet Office can cover most of the SES components. Therefore, to achieve the harmonization of uses and conservation (Article 2 of the Act), local government (Okinawa Prefecture, Ishigaki City), and the Cabinet Office (Headquarter for the Ocean Policy) can 
potentially play the central roles in the policy coordination and create the synergy effects. However, in reality, these organizations have smaller budgets, less staffs, and limited policy capacities compared to the sectoral ministries such as MoE, MAFF, MLIT, and MEXT. But they have advantages, as well. For example, local government has the local sense of the realities and the close connections to the local stakeholders. These are important and powerful advantages to codesign and coimplement the policy interventions. The Cabinet Office has the authority to coordinate other ministries, and it has the legal base to do that such as the Basic Ocean Plan of 2018 or the Marine Biodiversity Conservation Strategy, etc. Therefore, the more detailed analysis is required on how to design the multilevel governance framework for the effective ocean policy as a whole, and on the ideal role sharing and knowledge sharing scheme among the national government (including ministries), local government, local people, resource users, nongovernmental organizations, etc. (Jones 2014; Oyama 2017; Gerhardinger et al. 2018). Note that, as Makino et al. (2009) discussed, international organizations can sometimes play important roles to facilitate the multilevel and integrated governance within a country. Now, the Japanese government is planning to recommend this area to the UNESCO World Natural Heritage. The inscription to the Heritage List will bring additional effects for the ocean policy integration.

\subsubsection{Next Step}

This schematic is a qualitative expression of the interrelationships within the Sekisei Lagoon Social-Ecological Systems. Therefore, we cannot draw any lessons or implications about the cumulative effects or the trade-offs. Also, we cannot discuss the timescale issues or the magnitude of uncertainties or fluctuations within this schematic. In order to deal with these issues, quantitative model are needed. Also, we need the Geographical Information System (GIS) analysis to understand the spatial dynamics within the Sekisei Lagoon SES. However, taking the limitation of the research budget and human resources into account, it is neither realistic nor desirable to construct the detailed quantitative models for all the components of the Sekisei Lagoon SES. We need to set the priorities. In doing that, the SES Schematic can be utilized as a boundary object for local stakeholders, researchers, and decisionmakers to discuss together to identify which part of the Sekisei Lagoon SES should be deeply analyzed by the detailed quantitative models. This is how the SES Schematic analysis and the quantitative modeling analysis can be linked in a transdisciplinary research project.

By incorporating the future climate scenarios to the SES Schematic, we can discuss the potential effects to both the ecological and social system. Figure 2.9 is the preliminary results of such exercise. As experienced in the Great Barrier Reef, the climate change will trigger the mass breaching and death of the coral reef, which then lead to the cross-scale effects to the larger ecosystem (Stuart-Smith et al. 2018). The Sekisei Lagoon is the same. In 2016, a large-scale mass breaching were observed 


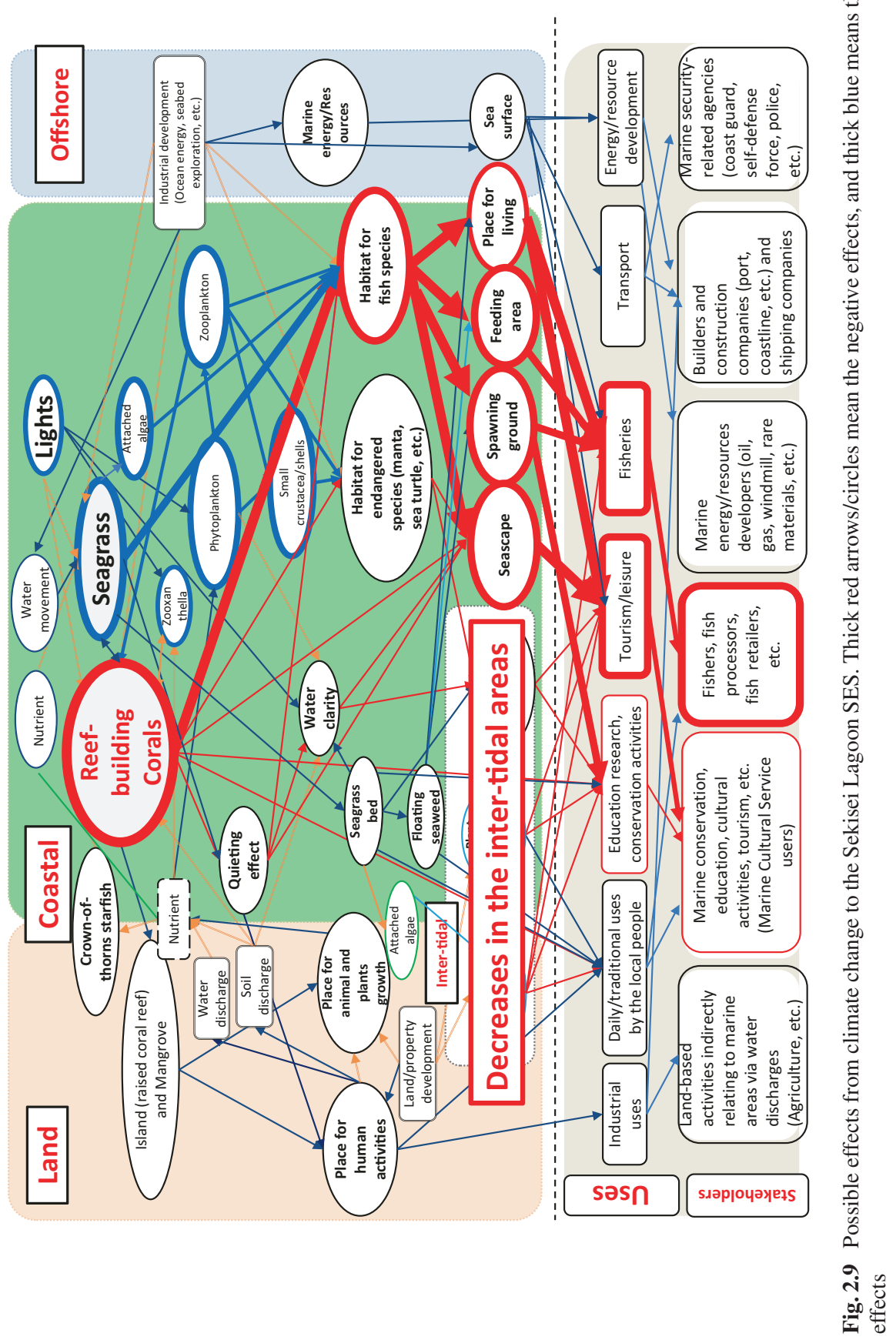


in Okinawa Prefecture because of the extraordinary high temperature and the less typhoon visits, which led to the less water mixing. According to the official monitoring results by the Ministry of Environment, mass breaching was observed at 82-90\% of the total area of the Sekisei Lagoon (Ministry of Environment 2018). If the climate change continues, the area of the coral reefs will be shrunken, and which leads to the decrease in the size of coral fish habitat Nanami et al. 2013), which then leads to the decrease in the spawning stock biomass of important fisheries resources (Nanami et al. 2015). Also, the higher water temperature leads to the changes in the spawning cycle, which presumably gives negative impact for spawning schooling (Ohta and Ebisawa 2017). These will give negative impacts to the fisheries and tourism sector. On the other hand, the higher water temperature positively effects to the seagrass bed at the coastal areas, which then positively effects to the fish biomass as the habitat for some species. Also, intertidal area will be shrunken by the sea level rise, which will again give negative effects to the traditional uses by the local people, as well as the environmental education, research and conservation activities. The cumulative effects to the total well-being and inclusive wealth (Ikeda and Managi 2018) are to be analyzed, but the SES Schematic is again a useful tool to share the knowledge with wide-ranging stakeholders, discuss about the vulnerable part of the SES, and codesign the possible future scenarios (Saito et al. 2018) or the adaptation plans.

Finally, after the development of the Sekisei Lagoon Social-Ecological Systems Schematic, the coauthor found that this type of co-research activity participated widely from both the natural and social sciences was a good opportunity for researchers to build a common sense at the larger conceptual level, and to create the knowledge base for working closely. Natural scientists can understand the links between their disciplinary study topics and the real society or the legal basis. Similarly, as discussed earlier, social scientists realized how the different stakeholders are interlinked at the ecosystem level. The coauthor also believe the developing process of the SES schematic will be utilized as the education program for students or the early career researchers who would like to conduct the interdisciplinary researches in the future.

Acknowledgments This study was funded by the Environment Research and Technology Development Fund (Strategic R\&D Category) of Ministry of the Environment, Japan, "Predicting and Assessing Natural Capital and Ecosystem Services (PANCES)”.

\section{References}

Armitage D, Charles A, Berkes F (eds) (2017) Governing the coastal commons: communities, resilience and transformation. Routledge, Oxford

Ban NC, Mills M, Tam J, Hicks CC, Klain S, Stoeckl N, Bottrill MC, Levine J, Pressey RL, Satterfield T, Chan KM (2013) A social-ecological approach to conservation planning: embedding social considerations. Front Ecol Environ 11(4):194-202

Berkes F, Armitage D, Ibarra MA, Charles T, Loucks L, Graham J, Seixas C, Makino M, Satria A, Abraham J (2014) Guidelines for analysis of social-ecological systems. http://www.communityconservation.net/ses-guidelines/. Accessed 18 Sept 2018 
Bodin O (2017) Collaborative environmental governance: achieving collective action in socialecological systems. Science 357:eaan114

Cash DW, Clark WC, Alcock F, Dickson NM, Eckley N, Guston DH, Jäger J, Mitchell RB (2003) Knowledge systems for sustainable development. Proc Natl Acad Sci 100(14):8086-8091

Cicin-Sain B, Knecht RW (1998) Integrated coastal and ocean management: concepts and practices. Island Press, Washington, DC

Cvitanovic C, Hobday AJ, van Kerkhoff L, Wilson SK, Dobbs K, Marshall NA (2015) Improving knowledge exchange among scientists and decision-makers to facilitate the adaptive governance of marine resources: a review of knowledge and research needs. Ocean Coast Manage 112:25-35

Diaz S et al (2018) Assessing nature's contributions to people: recognizing culture, and diverse sources of knowledge, can improve assessments. Science 359:270-272

Dunn WN (2016) Public policy analysis, 5th edn. Routledge, London

Ehler C (2014) A guide to evaluating marine spatial plans (IOC manuals and guides 70). UNESCO, Paris

Friedman K, Garcia SM, Rice J (2018) Mainstreaming biodiversity in fisheries. Mar Policy 95:209-220

Gerhardinger LC, Gorris P, Gonçalves LR, Herbst DF, Vila-Nova DA, De Carvalho FG, Glaser M, Zondervan R, Glavovic BC (2018) Healing Brazil's Blue Amazon: the role of knowledge networks in nurturing cross-scale transformations at the frontlines of ocean sustainability. Front Mar Sci 4:395

Guneroglu A (2015) Special issue: third international symposium on integrated coastal zone management (ICZM): towards sustainable coasts- "recent developments and advancements". Ocean Coast Manage 118:97-316

Hori J, Tajima H, Makino M (2017) The analysis of stakeholders' interests in coral reef ecosystems and their services-a case study on the Sekisei Lagoon. J Coast Zone Stud 30(2):61-73. (in Japanese)

Howard M, Davidson J, Lockwood M, Hockings M, Kriwoken L, Allchin R (2013) Climate change, scenarios and marine biodiversity conservation. Mar Policy 38:438-446

Ikeda S, Managi S (2018) Future inclusive wealth and human Well-being in regional Japan: projections of sustainability indices based on shared socioeconomic pathways. Sustain Sci. https:// doi.org/10.1007/s11625-018-0589-7

Jones PJS (2014) Governing marine protected Aras: resilience through diversity. Routledge, New York

Kittinger JN, Koehn JZ, Le Cornu E, Ban NC, Gopnik M, Armsby M, Brooks C, Carr MH, Cinner JE, Cravens A, Erikson A, Finkbeiner EM, Foley MM, Fujita R, Gelcich S, St Martin K, Prahler E, Reineman DR, Shackeroff J, White C, Caldwell MR, Crowder LB (2014) A practical approach for putting people in ecosystem-based ocean planning. Front Ecol Environ 12(8):448-456

Lou X, Li Y, Chen F (2017) Coral reef restoration in Sekisei Lagoon, Okinawa, Japan. In: Guillotreau P, Bundy A, Perry I (eds) Global challenge in marine system: integrating natural, social and governing responses. Routledge, Oxon, pp 282-294

Makino M (2011) Fisheries management in Japan: its institutional features and case studies. Springer, Dordrecht

Makino M, Matsuda H, Sakurai Y (2009) Expanding fisheries co-management to ecosystem-based management: a case in the Shiretoko world natural heritage, Japan. Mar Policy 33:207-214

Makino M, Hori M, Hori J, Nanami A, Tojo A, Tajima H (2018) Understanding the integrated policy for harmonizing the marine ecosystem conservation and sustainable uses: a case of Sekisei lagoon, Japan. Conference paper for OCEANS'18 MTS/IEEE Kobe/Techno-Ocean 2018, 28-31 May, Kobe

Ministry of Environment (2018) Press release: the monitoring results of the coral reef breaching phenomena around the Amami Island, Okinawa Island, Sekisei Lagoon and the Iriomote Island. http://www.env.go.jp/press/105831.html (in Japanese) 
Nanami A, Sato T, Takebe T, Teruya K, Soyano K (2013) Microhabitat association in whitestreaked grouper Epinephelus ongus: importance of Acropora spp. Mar Biol 160(6):1511-1517

Nanami A, Ohta I, Sato T (2015) Estimation of spawning migration distance of the white-streaked grouper (Epinephelus ongus) in an Okinawan coral reef system using conventional tag-andrelease. Environ Biol Fish 98(5):1387-1397

Ohta I, Ebisawa A (2017) Inter-annual variation of the spawning aggregations of the white-streaked grouper Epinephelus ongus, in relation to the lunar cycle and water temperature fluctuation. Fish Oceanogr 26(3):350-363

Ostrom E (2009) A general framework for analyzing sustainability of social-ecological systems. Science 325:419-422

Oyama K (2017) Concept of governance in the social-ecological system theory: IPBES, Ostrom, and public governance. Keio Univ Legal Stud 90(3):1-31. (in Japanese)

Reed MS, Stringer LC, Fazey I, Evely AC, Kruijsen JHJ (2014) Five principles for the practice of knowledge exchange in environmental management. J Environ Manag 146:337-345

Saito O, Kamiyama C, Hashimoto S, Matsui T, Shoyama K, Kabaya K, Uetake T, Taki H, Ishikawa Y, Matsushita K, Yamane F, Hori J, Ariga T, Takeuchi K (2018) Co-design of national-scale future scenarios in Japan to predict and assess natural capital and ecosystem services. Sustain Sci. https://doi.org/10.1007/s11625-018-0587-9

Sakamoto S (2018) Ocean policy and ocean Laws in Japan. Shinzansha, Tokyo

Schultz L et al (2015) Adaptive governance, ecosystem management, and natural capital. PNAS 112:7369-7374

Star SL, Griesemar JR (1989) Institutional ecology, 'transi-tions' and boundary objects: amateurs and professionals in Berkeley's Museum of Vertebrate Zoology, 1907-1939. Soc Stud Sci 19(3):387-420

Stuart-Smith RD, Brown CJ, Ceccarelli DM, Edgar G (2018) Ecosystem restructuring along the Great Barrier Reef following mass coral bleaching. Nature 560:92-96

Sugimoto A (2016) Fish as a 'bridge'connecting migrant fishers with the local community: findings from Okinawa, Japan. Maritime. Studies 15:5

Tiller RG, Kok J-LD, Vermeiren K, Thorvaldsen T (2017) Accountability as a Governance Paradox in the Norwegian Salmon Aquaculture Industry. Front Mar Sci 4:71

Weimer DL, Vining AR (2017) Policy analysis: concepts and practice, 6th edn. Routledge, New York

Open Access This chapter is licensed under the terms of the Creative Commons Attribution 4.0 International License (http://creativecommons.org/licenses/by/4.0/), which permits use, sharing, adaptation, distribution and reproduction in any medium or format, as long as you give appropriate credit to the original author(s) and the source, provide a link to the Creative Commons licence and indicate if changes were made.

The images or other third party material in this chapter are included in the chapter's Creative Commons licence, unless indicated otherwise in a credit line to the material. If material is not included in the chapter's Creative Commons licence and your intended use is not permitted by statutory regulation or exceeds the permitted use, you will need to obtain permission directly from the copyright holder.

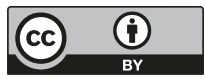

